Conference Proceedings Paper

\title{
CLLJ and WHWP heat content as a constrain to North American Monsoon activation moisture supply
}

\author{
Ana María Durán-Quesada ${ }^{1}$, Rodrigo Castillo ${ }^{2}$, Marie Hundsdoerfer ${ }^{3}$ and Luis \\ Gimeno ${ }^{4}$,
}

Published: 07/11/2017

Academic Editor: Victor Magaña

1 Atmospheric, Oceanic and Planetary Physics Department, School of Physics, University of Costa Rica, Costa Rica; ana.duranquesada@ucr.ac.cr

2 Atmospheric, Oceanic and Planetary Physics Department, School of Physics, University of Costa Rica, Costa Rica; rodrigo.castillorodriguez@ucr.ac.cr

${ }^{3}$ University of Kiel, Germany; marie.hu@ gmx.de

4 Environmentla Physics Laboratory, University of Vigo, Spain; 1.gimeno@uvigo.es

* Correspondence: ana.duranquesada@ucr.ac.cr; Tel.: +506-2511-50-96

\begin{abstract}
:
The study of the interaction of weather and climate features of the Intra Americas Sea have risen several fundamental questions in the recent decades. Here we focus on how the development of the North American Monsoon (NAM) is dominated by the Caribbean and tropical Atlantic. Using a long term basis analysis of moisture supply to the NAM domain based upon FLEXPART Lagrangian trajectories, the role of the moisture supply from the Caribbean Sea and the Gulf of Mexico previous to the monsoon onset is analyzed. Regardless the NAM area requires the input from other sources, it is the eastern source which provides the required supply to activate the land moisture processes over the Sierra Madre region. In this work we explore how the Western Hemisphere Warm Pool (WHWP) increases the moisture content of the lower troposphere. The role of the Caribbean ow Level Jet (CLLJ) as a moisture conveyor to the eastern Sierra Madre region is also analyzed. The study includes an insight of the moisture transport process under warm and cold ENSO events.
\end{abstract}

Keywords: rainfall; monsoon; moisture transport; CLLJ; WHWP; ENSO 
The 1st International Electronic Conference on Hydrological Cycle (CHyCle-2017), 12 - 16 November 2017; Sciforum Electronic Conference Series, Vol. 1, 2017

\section{Introduction}

At the end of boreal spring, a monsoon-like anticyclone develops near the south of Mexico (at 200hPa) with a northward migration. The anticyclone is associated with heavy rainfall over north-western Mexico and south-western United States of America. This seasonal feature, known as the North American Monsoon (NAM) accounts for approximately $40 \%$ of the summer local rainfall and even up to $70 \%$ in some regions of Mexico [1]. Different analysis of the sources of moisture for the NAM have shown that the overall moisture input for the monsoon is composed by local continental evaporation and transport from adjacent oceanic regions [2] [3]. Previous studies have highlighted the importance of the Gulf of Mexico as a moisture source [4] [5]. Despite several aspects of the NAM such as rainfall intensity effects [6], sensitivity to interannual variability [7] and climate influence [8] modes are relatively well known, few studies have addresses the role of the moisture supply for the monsoon activation. Based on observational datasets, the moisture flux was analyzed by [9], and his results showed that moisture flux from the Gulf of Mexico across the Tehuantepec region was sustained during the rainy period. The distribution of SST has been also subject of analysis regarding the NAM, [2] analyzed how the tropical Pacific SSTs play a role through different teleconnection patterns to changes in the monsoon ridge position. Here we combine a Lagrangian trajectories based analysis of moisture sources for precipitation on the NAM core with WHWP and CLLJ indices as well as gridded rainfall products to evaluate to which extent the WHWP and the CLLJ may modulate the moisture supply from the eastern source, namely Gulf of Mexico, during the NAM. In addition, the response of the sources of moisture to low frequency variability modes is also considered.

\section{Data and Methods}

The present study includes different precipitation products, reanalysis, climate indices (summarized in Table 1) as well as a Lagrangian backward trajectories dataset.

Table 1. Datasets used in this study.

\begin{tabular}{cccc}
\hline Variable & Dataset & Resolution & Reference \\
\hline precipitation & CHIRPS & Daily & {$[10]$} \\
& & $0.05^{\circ}$ gridded & \\
SST & OAFlux & $1^{\circ}$ gridded & {$[11]$} \\
Zonal wind & ERA Interim & $0.75^{\circ}$ gridded & {$[12]$} \\
MEI index & - & monthly & {$[13]$} \\
PDO index & - & monthly & {$[14]$} \\
\hline
\end{tabular}


The zonal wind was used to compute the Caribbean Low Level Jet (CLLJ) index, defined as the area averaged of zonal wind between $12 \mathrm{~N}-16 \mathrm{~N}$ and $80 \mathrm{~W}-70 \mathrm{~W}$. With the OAFlux SST dataset, two separate indices for the Pacific and Atlantic components of the WHWP were computed as the area enclosed by the $28.5 \mathrm{C}$ isotherm following [15]. The global Lagrangian backward trajectories dataset computed using the Lagrangian particle dispersion model FLEXPART version 8 [16]. The model was initialized with ERA-Interim Reanalysis data [12] using analysis every $6 \mathrm{~h}$ and 3-hourly forecasts at the intermediate times as explained in [17]. The method developed by [18] was implemented to identify the sources of moisture linked to the NAM core area (shown in red in Figure 1) during the days that rainfall exceeded a threshold of $5 \mathrm{~mm} /$ day based on gridded precipitation [10].

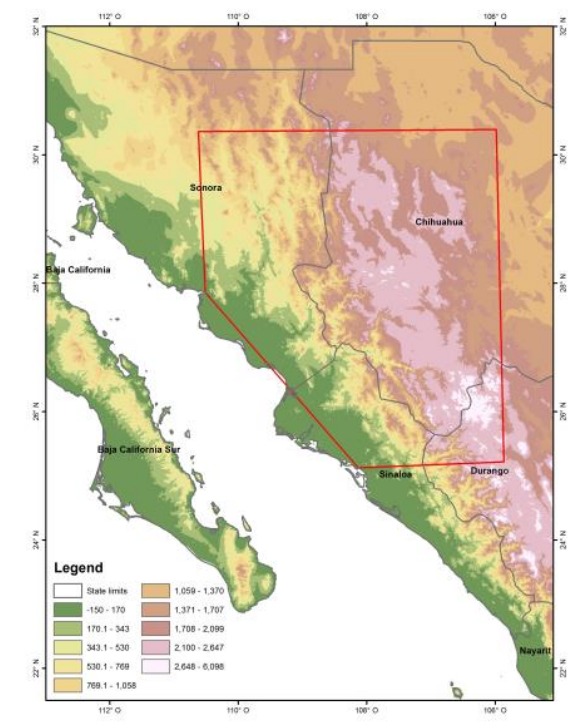

Figure 1. The NAM core analysis area was defined for the region for which the heaviest rainfall is observed during the active rainy season. Backward trajectories analysis was performed considering the red line polygon as target area of the moisture sources supply. It is worth noticing that the analysis region includes the western portion of the Sierra Madre mountain range and extends over part of the western Sonoran Desert.

\section{Results and discussion}

The tropical belt is featured by a maximum of incoming solar radiation (ca. 240 $\mathrm{Wm}^{2}$, in the IAS region, the SST is warmer in the vicinity of the eastern tropical Pacific, the Caribbean Sea and the Gulf of Mexico. The warmer SST region is regarded as the WHWP and has been defined as enclosed by the $28.5 \mathrm{C}$ isotherm [15]. It is the second largest warm water body on Earth after the Indo-Pacific Warm Pool and has a marked seasonal cycle. Warmer temperatures are phased sequentially from the Eastern North Pacific (ENP) and west of Central America to the IAS. Figure 2 shows the long term mean averaged area of the Pacific (A) and Atlantic (B) components of the WHWP. The activation of the Pacific component during the spring time is clear, however the Atlantic component, active during summer, doubles the size of the Pacific counterpart. 
The 1st International Electronic Conference on Hydrological Cycle (CHyCle-2017), 12 - 16 November 2017;

Sciforum Electronic Conference Series, Vol. 1, 2017
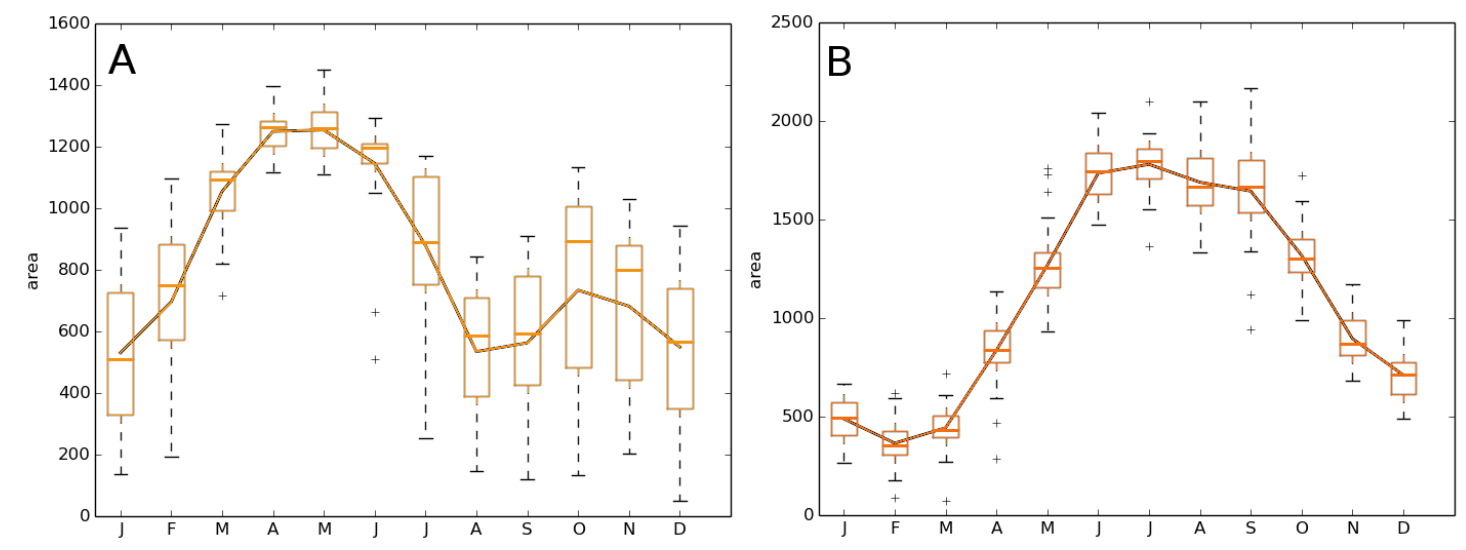

Figure 2. Long term mean annual cycle of the area enclosed by the $28.5 \mathrm{C}$ isotherm for the eastern tropical Pacific (A) and the Caribbean Sea (B) computed from the OAFlux dataset for the 1980-2015 time span.

The long term mean moisture flux analysis is featured by convergence/divergence pattern between western Mexico and the region extending from the Gulf of Mexico to north-eastern Mexico. The trajectories based analysis show that considering the 10 days history of the air particles, the moisture exports peak at 6 days and after the $6^{\text {th }}$ day the additional moisture supply decreases significantly from the oceanic sources. During late spring, as the NAM activates, local moisture surface exports and evaporation over the Gulf of California represent the main moisture source for the NAM core region. Notice however that the moisture sources analysis for the NAM region is focused on the oceanic sources, since continental moisture supply relies on evapotranspiration which is not resolved with the implemented methodology. As the rainfall over the NAM region increases, the Pacific slope moisture supply decreases and exports from the Gulf of Mexico and the Caribbean Sea become a significant contribution. The oceanic sources of moisture follow the warmer SSTs distribution in the region and their annual cycle nearly follows the WHWP components. Moisture from the Gulf of Mexico and the Caribbean Sea becomes important during July, as the moisture transport is sustained by the northward branch of the CLLJ.
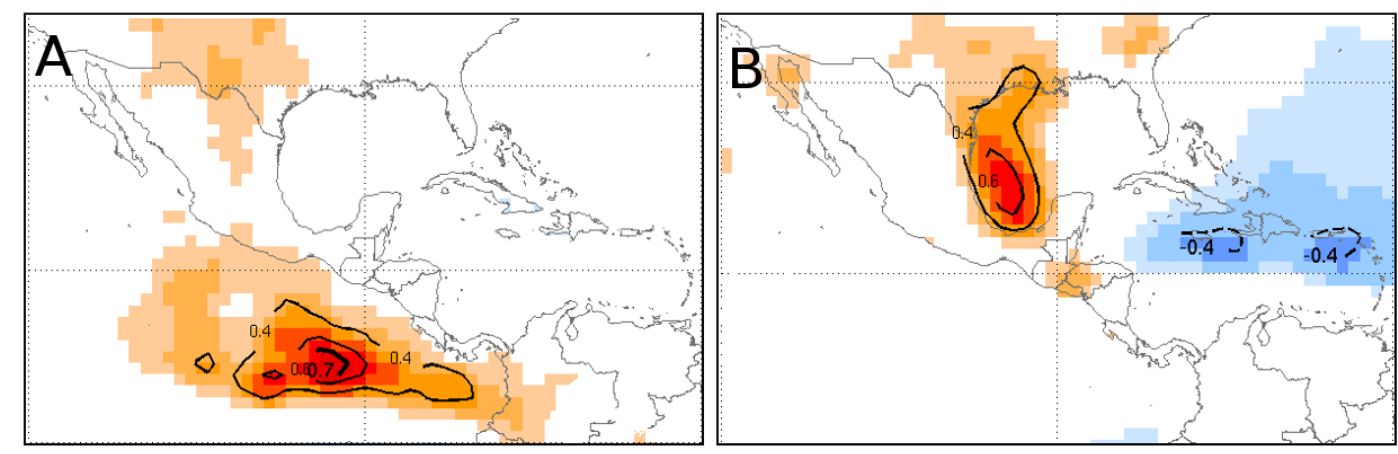

Figure 3. Spatial correlation between the overall moisture supply from the Gulf of California (A) and the Gulf of Mexico (B) with SST during May (A) and June (B). 
Despite the Atlantic component of the WHWP sustains the moisture flow to the western Sierra Madre aided by the CLLJ as a conveyor structure, it is the development of the Pacific component which provides favorable warm SSTs south of the Gulf of California. Figure 3 shows a large relationship between the late spring time moisture supply from the Gulf of California with the Pacific component of the WHWP, whereas moisture supply from the Gulf of Mexico is strongly favored by the summer shifting of the Atlantic WHWP component.

Besides the average moisture supply to the NAM development, the effect of ENSO is also considered. Here we focus on the structure of the moisture transport from the Gulf of Mexico and the inner Caribbean region (averaged between 10 and $28 \mathrm{~N}$ ) during summer, period of the CLLJ main peak. During the peak of the NAM, influence of the cold phase on the moisture supply from the Gulf of California is relatively small compared to the mean climatology. The effect of ENSO for the Gulf of Mexico source is larger. The overall contributions from the Gulf of Mexico and the Caribbean Sea increase during July for warm ENSO events. Figure 4 shows the vertical structure of composited cold A (warm B) ENSO events for July along with composited averaged zonal wind. Results show how moisture transport doubles its intensity during warm ENSO compared to cold events. The increase in the moisture supply from the Gulf of Mexico and the Caribbean Sea to the NAM core is strongly sensitive to the nearly $2-3 \mathrm{~m} / \mathrm{s}$ average increase in the zonal easterly winds.
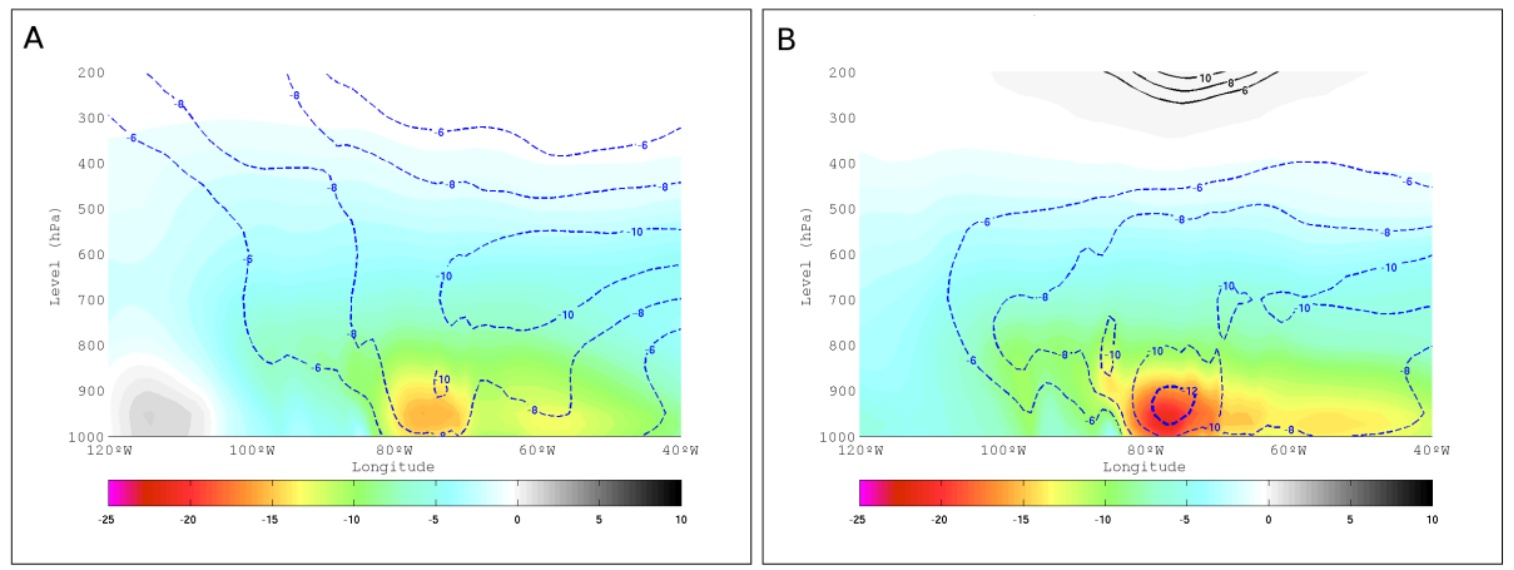

Figure 4. Vertical structure of moisture transport for cold (A) and warm (B) ENSO events during July shown in shaded contours (color scale for easterly flow and gray scale for westerly flow). Line contours for composited zonal winds averaged between 10 and $15 \mathrm{~N}$. 
The 1st International Electronic Conference on Hydrological Cycle (CHyCle-2017), 12 - 16 November 2017; Sciforum Electronic Conference Series, Vol. 1, 2017

\section{Conclusions}

The implemented approach is useful to evaluate general features of the moisture supply during the monsoon development. It also gives a good representation of the variability of the NAM in terms of the contributions to precipitation from the oceanic sources of moisture. The good agreement between the results derived from the moisture supply estimates and different studies performed on the variability of the NAM is encouraging on the application of this methodology. The WHWP plays a relevant role for the NAM rain as it provides moisture for the NAM activation from its Pacific component late in spring and later on in summer the Atlantic component provides moisture to sustain the supply to the eastern Sierra Madre region.

Acknowledgments: This research was supported by the UCR- grant project B5601 Monsoon flow variability: impact on rainfall from global to regional scales.

Author Contributions: A.D. and L.G. conceived and designed the experiments; A.D. performed the experiments; A.D., L.G and R.C. analyzed the data; M.H. supported WHWP indices computation and data analysis; A.D. wrote the paper.

Conflicts of Interest: The authors declare no conflict of interest.

\section{References}

[1] Douglas, M.W., Maddox, R.A., Howard, K. and Reyes, S., 1993. The mexican monsoon. Journal of Climate, 6(8), pp.1665-1677.

[2] Castro, C.L., McKee, T.B. and Pielke Sr, R.A., 2001. The relationship of the North American monsoon to tropical and North Pacific sea surface temperatures as revealed by observational analyses. Journal of Climate, 14(24), pp.4449-4473.

[3] Dominguez, F., Kumar, P. and Vivoni, E.R., 2008. Precipitation recycling variability and ecoclimatological stability-A study using NARR data. Part II: North American monsoon region. Journal of Climate, 21(20), pp.5187-5203.

[4] Higgins, R.W., Yao, Y. and Wang, X.L., 1997. Influence of the North American monsoon system on the US summer precipitation regime. Journal of Climate, 10(10), pp.2600-2622.

[5] Knippertz, P. and Wernli, H., 2010. A Lagrangian climatology of tropical moisture exports to the Northern Hemispheric extratropics. Journal of Climate, 23(4), pp.987-1003.

[6] Mazon, J.J., Castro, C.L., Adams, D.K., Chang, H.I., Carrillo, C.M. and Brost, J.J., 2016. Objective Climatological Analysis of Extreme Weather Events in Arizona during the North American Monsoon. Journal of Applied Meteorology and Climatology, 55(11), pp.24312450.

[7] Higgins R, Shi W. Intercomparison of the principal modes of interannual and intraseasonal variability of the North American monsoon system. Journal of Climate. 2001 Feb;14(3):403-17. 
The 1st International Electronic Conference on Hydrological Cycle (CHyCle-2017), 12 - 16 November 2017; Sciforum Electronic Conference Series, Vol. 1, 2017

[8] Szejner P, Wright WE, Babst F, Belmecheri S, Trouet V, Leavitt SW, Ehleringer JR, Monson RK. Latitudinal gradients in tree ring stable carbon and oxygen isotopes reveal differential climate influences of the North American Monsoon System. Journal of Geophysical Research: Biogeosciences. 2016 Jul 1;121(7):1978-91.]

[9] Berbery, E.H., 2001. Mesoscale moisture analysis of the North American monsoon. Journal of Climate, 14(2), pp.121-137.

[10] Funk, C., Peterson, P., Landsfeld, M., Pedreros, D., Verdin, J., Shukla, S., Husak, G., Rowland, J., Harrison, L., Hoell, A. and Michaelsen, J., 2015. The climate hazards infrared precipitation with stations-a new environmental record for monitoring extremes. Scientific data, 2, p.150066.

[11] Jin, X. and Weller, R.A., 2008. Multidecade global flux datasets from the Objectively Analyzed Air-sea Fluxes (OAFlux) project: Latent and sensible heat fluxes, ocean evaporation, and related surface meteorological variables lisan yu. OAFlux Project Tech. Rep. OA-2008-01, 74.

[12] Dee DP, Uppala SM, Simmons AJ, Berrisford P, Poli P, Kobayashi S, Andrae U, Balmaseda MA, Balsamo G, Bauer P, Bechtold P. The ERA-Interim reanalysis: Configuration and performance of the data assimilation system. Quarterly Journal of the royal meteorological society. 2011 Apr 1;137(656):553-97.

[13] Wolter, K., and M.S. Timlin, 1998: Measuring the strength of ENSO - how does 1997/98 rank? Weather, 53, 315-324.

[14] Mantua, N.J. and S.R. Hare, Y. Zhang, J.M. Wallace, and R.C. Francis,1997: A Pacific interdecadal climate oscillation with impacts on salmon production. Bulletin of the American Meteorological Society, 78, pp. 1069-1079.

[15] Wang, C., and D.B. Enfield, 2001: The tropical Western Hemisphere warm pool, Geophys. Res. Lett., 28, 1635-1638.

[16] Eckhardt, S., Stohl, A., Sodemann, H., Frank, A., Seibert, P., and Wotawa, G.: The Lagrangian particle dispersion model FLEXPART version 8.0, Tech. rep., Norwegian Institude of Air Research, 2008

[17] Durán-Quesada, A.M., Gimeno, L. and Amador, J., 2017. Role of moisture transport for Central American precipitation. Earth System Dynamics, 8(1), p.147.

[18] Stohl, A. and James, P.: A Lagrangian analysis of the atmospheric branch of the global water cycle. Part I: Method description, validation, and demonstration for the August 2002 flooding in central Europe, J. Hydrometeorol., 5, 656-678, 2004.

(C) 2017 by the authors; licensee MDPI, Basel, Switzerland. This article is an open access article distributed under the terms and conditions of the Creative Commons by Attribution (CC-BY) license (http://creativecommons.org/licenses/by/4.0/). 